A ação política do MST, Movimento dos Sem Terra, tirante os radicalismos de alguns de seus ativistas e dirigentes, revelou a capacidade organizativa da sociedade, pois o MST não só levou à necessidade de intensa intervenção governamental na desapropriação de terras e assentamento de famílias de agricultores, como a cada momento o Movimento expande suas reivindicações, revelando extraordinária capacidade de alistamento de pessoas para integrar seus quadros. A atividade educativo-escolar promovida pelo Movimento em favor dos filhos dos "sem terra" bem revela a visão ampla que orienta a organização.

A experiência do Orçamento Participativo na prefeitura de Porto Alegre vem a ser a melhor demonstração da participação política no centro do processo decisório definidor da ação governamental, experiência esta a ser pensada, sem dúvida com maiores dificuldades, para os níveis mais amplos da Administração, Estados e União.

Estado e Comunidade deve ser o binômio básico ${ }^{29}$, pois só pela interação de ambos na formulação e consecução de políticas sociais construir-se-á a cidadania.

A solução está, portanto, mais adiante da representação política e da atividade partidária. É essencial, todavia, que a classe política tenha a sensibilidade de não pretender manter o monopólio da ação política, pelo exclusivismo dos tradicionais canais institucionais. Só assim se viabilizará uma maior mobilização da sociedade em prol de interesses gerais dos indivíduos, e em especial com vista à maioria dos excluídos, enquanto titulares de direitos fundamentais. Whese apresentada à Conferência Nacional dos Advogados, em 1982 sob o título, Justiça social e participação política, defendia que se instituísse um Conselho Econômico-Social, composto por ministros da área econômica, representante de partido da oposição, representantes de trabalhadores da indústria, do comércio e do campo, bem como por representantes da classe empresarial fixando programas e metas, a serem depois submetidos ao Congresso. FABIO KONDER COMPARATO em tese apresentada à Conferência Nacional dos dência Nacional de Planejamento, assessorada por um Conselho Nacional de Planeja de uma Superintenrepresentantes de sindicatos e organizaç̃os profissionais para elaboraça nacional de desenvolvimento, a ser aprovado pelo Congresso Nacional. (Anais da X Conferência Nacional dos Advogados, p. 99). Nesta mesma X Conferência propunha eu, com a tese, "Sociedade Civil e Estado" igualmente a criação de um Conselho Consultivo de Economia. (anais, cit. p. 76).

Revista da Faculdade de Direito da UFRGS, v. 21, Março/2002

\title{
Breve Reseña de La Legislacion Para La Reactivacion de Las Pymes Durante La Ultima Decada de Los 90
}

\author{
Monica B. Hise y M. Fernanda Moreno
}

\section{I - Introduccion}

El presente trabajo tiene por objetivo analizar el tema concerniente al fenómeno de las PyMEs en nuestro país, fundamentalmente trataremos de ver como se llega a la ley 24.467 , y que modificaciones sufrió luego de su sanción.

Desde ya queremos adelantar que, esta ley ha tenido un sin número de modificaciones entre leyes, decretos, resoluciones y decisiones administrativas.

A fin de que el presente trabajo resulte de fácil comprensión sólo analizaremos las modificaciones más importantes y recientes, sin perjuicio de que adjuntamos un anexo, conteniendo todas las modificaciones existentes en la actualidad.

\section{II - Antecedentes, Sancion Y Caracteristicas de La Ley 24.467}

El fenómeno de las Pymes no es nuevo, si bien el mayor auge aparece a partir de la sanción de la ley 24.467, existía a nivel legislativo una profunda preocupación por este tema.

Esto se pone de manifiesto a través de los numerosos decretos, resoluciones y leyes que se referían a este tema ${ }^{1}$.

Cabe destacar que antes de la sanción de la ley 24.467, la legislación existente no hacía diferencia entre las grandes empresas pequeñas empresas - ej. La ley de Sociedades 19.550 o la ley de Concursos 24.522 salvo los arts. 288 y 289 , de Lealtad Comercial, de Transferencia Tecnológica, etc.

Decreto 2732/93 del MEOSP referente a la pequeña y mediana empresa; Decreto 376/94 MEOSP respecto a los créditos para la pequeña y mediana empresa; Decreto 1002/94 MEOSP Créditos al Fomento; Resolución 99/ 95 de la Secretaría de Turismo - Habilitación. Registro. Consorcios de Pequeña y Mediana Empresa. 
Sin embargo las prácticas mercantiles comienzan a requerir un tratamiento específco y particular para un buen funcionamiento $y$ adecuado desarrollo de las pequeñas empresas, ya que sus necesidades, características y posibilidades en el mercado difiere en relación con las grandes empresas.

Así llegamos a que el 15 de Marzo de 1995 se sanciona la ley 24.467.2 "DISPOSICIONES PARA PEQUEÑAS Y MEDIANAS EMPRESAS (PyMES)”.

Es la primera ley que se dedica exclusivamente a las Pequeñas y medianas empresas.

Según comentario de Farina, Fernandez Campeon y Rainolter, el principal objetivo de esta ley ha sido facilitar el acceso de las PyMEs al crédito bancario, y prometer alguna bonificación en las tasas de interés.

Esta ley no es un estatuto de las PyMEs no regula la constitución, ni el funcionamiento, no contiene norma alguna que modifique alguna disposición contenida en las leyes y códigos que constituyen al derecho positivo vigente en la Argentina. La ley 24.467 procura otorgar cierta organicidad a la política que debe seguir desplegando el Poder Ejecutivo nacional para promover el crecimiento y desarrollo de estas empresas, pero ninguna pequeña o mediana empresa está obligada a calificarse como tal $\mathrm{n}$ inscribirse en el Registro Nacional de PyMEs, salvo que pretenda ser beneficiaria de alguna de las ventajas que prevé esta ley.

Tampoco esta ley entra a tutelar a las PyMEs frente a las condiciones a veces

2 Ley. 24.467. Sancionada 15/03/95. Prom.: 23/03/95.- Public. B.O. 28/03/95.- Modificada por Ley 25.300 y 25.013 .

${ }^{3}$ Régimen de Pequeñas y Medianas Empresas. Ley 24.467. Comentada y Concordada con los decretos reglamentarios 737/95 y 908/95. Consorcio de PyMEs. Sociedad de garantía recíproca, beneficios económicos, impositivos y labora

${ }^{4}$ Titulo I: Disposiciones generales (arts. $1^{\circ} \mathrm{a} 31$ )

Titulo II: Sociedades de garantía recíproca (arts. 32 a 82)

Revista da Faculdade de Direito da UFRGS, v. 21, Março/2002

Esta ley, se compone de tres títulos.

Los títulos I y II ${ }^{4}$, se refieren concretamente a aspectos económicos de las PyMEs, las disposiciones contenidas en estos títulos son aplicables a todas las empresas, sean civiles o comerciales, que reúnan las condiciones para ser calificadas como micro, pequeñas y medianas Empresas.

Han sido reglamentados por el decreto $908 / 95$
En cuanto a la autoridad de aplicación ha variado a lo largo de los años. En un primer momento fue el Ministerio de Economía y Obras y Servicios Públicos a través de la Secretaría de Industria. En virtud del decreto 660/96 estas funciones se le atribuyeron a la Secretaria de Industria, Comercio y Minería.

$\mathrm{Al}$ sancionarse la ley $25.300^{5}$ - Fomento para la Micro, Pequeña y Mediana Empresa-, que modifica gran parte de los artículos comprendidos en estos títulos ${ }^{6}$, se designa autoridad de aplicación a la Secretaria de la Pequeña y Mediana Empresa del Ministerio de Economía.

Mientras que el título $\mathrm{III}^{7}$ se ocupa específicamente de las relaciones de trabajo en las pequeñas empresas, abarca todas las actividades que encuadran en la conceptualización dada por el art. $5^{8}$ de la LCT (sea civil, comercial, de artesanos, con o sin fines lucrativos) y que se halle comprendida en la categoría de pequeña empresa conforme los requisitos del art. 83 de la ley 24.467 .

En lo que atañe a las relaciones jurídico-

laborales en las pequeñas empresas, hay que tener presente que el marco regulatorio general es la ley de Contrato de Trabajo Nro. 20.744 (t.o. 1976) y sus modificatorias. También resultan de aplicación las disposiciones contenidas en la Ley Nacional de Empleo Nro. $24.013^{9}$, en la Ley de Flexibilización Laboral Nro. $24.465^{10}$, en la Ley de Reforma Laboral Nro. $25.013^{11}$, en la Ley $25.250^{12}$.

Este título III ha sido reglamentado por el Decreto 737/95, el decreto 1555/96, la Resolución del Ministerio del Trabajo y Seguridad Social 1/95, La Resolución de la DGI 4083/95 y el Decreto 16/99.

\section{IV - Analisis de La Ley}

Dadas las características del presente trabajo no haremos un análisis pormenorizado de las disposiciones contenidas en la ley, sino simplemente haremos referencia al contenido de cada título, y en lo posible mencionaremos cuales han sido las modificaciones que ha sufrido.

Reglamentada por Resolución 24/0

${ }^{6}$ Ley 25.300.- Artículos que modifica de la ley 24467.-: del Título I: 3 ; 12; 13; 14; Del Título II: 34; 37; 40; 42 . 43 agrega párrafo; 45 ; 46 agrega párrafo; 47 agrega párrafo; $49 ; 52 ; 55 ; 61 ; 79 ; 80$

7 Titulo III: Relaciones de trabajo (arts. 83 a 106)

${ }^{8}$ LEY 20744 art. 5: "A los fines de esta ley, se entiende como 'empresa' la organización instrumental de medios personales, materiales e inmateriales, ordenados bajo una dirección para el logro de fines económicos benéficos"

9 Ley 24013.- Sancionada 13/11/91.- Promulgada parcialmente: 05/12/91. Public. B.O. 17/12/91.

${ }^{10}$ Ley 24.465.- Nuevo Regimen de Contrato de Trabajo.- modificada por Ley 25.013.- Sancionada 15/03/95. Prom. 23/03/95. Public. B.O. 28/03/95.

${ }^{11}$ Ley 25.013.- Modificada por ley 25.250.- Sancionada 02/09/98. Promulgada parcialmente 22/09/98. Pulic B.O. $24 / 09 / 98$.

Ley 25.013 , deroga el art. 89 de la ley 24.467 .

${ }_{12}$ Ley 25.250 .-Reforma Laboral Estímulo al empleo estable. Período de prueba. Convenciones colectivas. Modifica ley. 23.546. Sancionada 11/05/2000, Promulgada 29/05/2000. Public. B.O. 02/06/2000. 


\section{A. TITULO I}

Como ya lo mencionáramos, éste título, que se lo ha denominado: DISPOSICIONES GENERALES, comprende desde el art. $1^{\circ}$ al 31 , se encuentra dividido en cinco secciones. Cuyos acápites secciones son los siguientes: I - Objeto, II - Definición de PyMEs, III - Instrumentos, IV-Autoridad de aplicación, V - De forma.

\section{I - Objeto}

En cuanto al objeto de la Ley se observa que es «promover el crecimiento y desarrollo de las pequeñas y medianas empresas impulsando para ello políticas de alcance general a través de la creación de nuevos instrumentos de apoyo y la consolidación de los ya existentes».

La ley impulsa a que el Poder Ejecutivo a través de decretos o resoluciones cree nuevos instrumentos de apoyo para incentivar el crecimiento y desarrollo de las PYMES.

La Ley no es operativa sino programática instaura un programa de acción que no se encuentra en manos del Congreso Nacional

\section{II - Definición}

El art. 2 de la ley pese a su denominación -definición de PyMEs- no da una definición sino que solo encomienda a la autoridad de aplicación que defina las características de las empresas que serán consideradas PyMEs, teniendo en cuenta las peculiaridades de cada región del país, y los diversos sectores de la economía en que se desempeñan, sin perjuicio de lo dispuesto por el art. 83 .
La primera aclaración que debemos hacer es la siguiente, el art. 83 se encuentra ubicado en el título III, y alude a las relaciones de trabajo, reglamentado específicamente por decreto $737 /$ 95 , estableciendo un régimen laboral de regulación especial, y la autoridad de aplicación conforme lo estipulado en el Reglamento es e Ministerio de Trabajo y Seguridad Social. Tema sobre el cual volveremos.

Sin perjuicio de que se fueron sancionando distintos decretos y resoluciones a fin de dar una definición de que empresas eran consideradas PyMEs, la ley 25.300 , cuyo objetivo es afianzar el fortalecimiento competitivo de las Micro, Pequeñas y Medianas Empresas, en su art. 1 dispone que la autoridad de aplicación deberá definir las características de las empresas que serán consideradas micro, pequeñas y medianas empresas a los efectos de poder aplicar las disposiciones allí contenidas.

Se dejó constancia que no serán consideradas MIPyMEs a los efectos de la implementación de los distintos instrumentos del régimen legal, las empresas que, aún reuniendo los requisitos cuantitativos establecidos por la autoridad de aplicación, estén vinculadas o controladas por empresas $o$ grupos económicos nacionales o extranjeros que no reúnan tales requisitos.

$\mathrm{Y}$ los beneficios vigentes para las MIPyMEs serán extensivos a las formas asociativas conformadas exclusivamente por ellas, tales como consorcios, uniones transitorias de empresas, cooperativas, y cualquier otra modalidad de asociación lícita.

Dicho art. 1 fue reglamentado por la resolución 24/2001, del 15/02/01 ${ }^{13}$.

${ }^{13}$ El Decreto 748/2000, que crea el "Programa de estímulo al crecimiento de las micro, pequeñas y medianas empresas (MIPyMEs) dispone lo mismo que ésta resolución que estamos comentando.

Revista da Faculdade de Direito da UFRGS, v. 21, Março/2002

En su art. 1, ésta resolución dispone que «A los efectos de lo dispuesto por el art. 1 del Título I de la Ley 25.300, serán consideradas Micro, Pequeñas y Medianas Empresas aquellas que registren hasta el siguiente nivel máximo de valor de las ventas totales anuales, excluido el Impuesto al Valor Agregado y el impuesto interno que pudiere corresponder, expresado en PESOS (\$).

\begin{tabular}{|c|c|c|c|c|}
\hline Tamaño / Sector & Agro-Pecuario & \begin{tabular}{|l|l|}
$\begin{array}{l}\text { Industria } \\
\text { Minería }\end{array}$ \\
\end{tabular} & Comercio & Servicios \\
\hline MICROEMPRESA & $\$ 150.000$ & $\$ 500.000$ & $\$ 1.000 .000$ & 250.000 \\
\hline $\begin{array}{l}\text { PEQUENA } \\
\text { EMPRESA }\end{array}$ & $\$ 1.000 .000$ & $\$ 3.000 .000$ & $\$ 6.000 .000$ & $\$ 1.800 .000$ \\
\hline MEDIANA EMPRESA & $\$ 6.000 .000$ & $\$ 24.000 .000$ & $\$ 48.000 .000$ & $\$ 12.000 .000$ \\
\hline
\end{tabular}

Asimismo, aclara que:

- Se entenderá por valor de las ventas totales anuales: el valor que surja del consignado en el último balance o información contable equivalente, adecuadamente documentada.

Cuando una empresa tenga mas ventas por más de uno de los rubros establecidos en el art. 1, se considerará aquel cuyas ventas hayan sido las mayores durante el último año.

- Que no serán consideradas MIPyMEs aquellas que reuniendo las condiciones establecidas en la presente resolución, se encuentren controladas o vinculadas por empresas o grupos económicos que no reúnan tales requisitos.

- Que esta resolución es de tipo general y no limita las facultades de los distintos organismos para completarla con precisiones o condiciones cualitativas adicionales o para fijar límites inferiores con respecto a los establecidos en el art. 1, a los efectos de instrumentar programas específicos relacio- nados con dicho estrato empresario y en regiones cuyas especificidades propias así lo requieran.

- Para las empresas recientemente constituídas, y a fin de determinar su pertenencia, se tomarán de los valores proyectados por la empresa para el primer año de actividad de la misma. Dichos valores tendrán el carácter de declaración jurada y estarán sujetos a verificación al finalizar el primer año de ejercicio. Al cabo de dicho período si resulta que la empresa no califica dentro del segmento MIPyMEs, deberá reintegrar o compensar los beneficios que hubiere obtenido en dicha calidad según criterio que establezca la autoridad de aplicación de dichos beneficios.

\section{III - Instrumentos}

El art. 3 de la ley 24.467 , que fue modificado por la ley 25.300 , establece que a fin de disminuir el costo del crédito se instituye un régimen de bonificación de tasas de interés, y 
el monto de la bonificación se establecerá en la respectiva reglamentación.

Asimismo, se favorecerá con una bonificación especial a las MIPyMEs nuevas o en funcionamiento localizadas en ámbitos geográficos que reúnan algunas de las siguientes características:

- regiones que registren tasas de crecimiento de actividad económica inferiores a la media nacional

- y a las que registren tasas de desempleo superiores a la media nacional

Esta bonificación será solventada por el Estado Nacional y se especifica el destino de crédito $^{14}$.

Se estipula que el Estado estimulará a la creación en el ámbito privado de sociedade calificadoras de riesgo crediticio de las pequeñas y medianas empresas con el objeto de facilitar su operatoria financiera y comercia (Art. 8). Estas evaluarán el desempeño, la solidez y el riesgo crediticio de las PYMES. El decreto reglamentario (908/95) impone dos requisitos a estas sociedades que son: a) que se encuentren inscriptas en el registro previsto en el decreto $656 / 92 \mathrm{y}$ b) que cuenten con un ma- nual de procedimientos específicos para la evaluación de las pequeñas y medianas empresas aprobado por la Comisión Nacional de Valores.

Esta calificación permite que las entidades bancarias y financieras puedan obtener informes respecto al grado de confiabilidad que merece la PYME

Conforme el art. 12 (ref. por ley 25.300) ordena crear un sistema de información de MIPyMEs, el que tendrá por objetivo la recolección y difusión de información comercial, técnica y legal que se juzgue de interés.

Asimismo se proveé la organización de una red de agencias regionales de desarrollo productivo a fin de brindar asistencia homogénea a las MIPyPEs.

Una de las innovaciones que parecieran ser viable es la formación de consorcios de empresas PYMES, que representaría una concentración de empresas que continuan manteniendo su individualidad jurídica y autonomía funcional a los fines de exportar orientándose a las economías de escala, aprovechando las ventajas comparativa (Art. 19Ley 24.467). a.- Créditos para la adquisición de bienes de capital propios de la actividad de la empresa; b.- para la constitución de capital de trabajo; c.- para la reconversión y aumento de la productividad debiendo además contemplar amplios plazos de amortización, tasas comparables a las más bajas de plaza y períodos de gracia según el retorno de la inversión previsto; d.- para la actualización y modernización tecnológica, de procedimientos administratiprefinanciar las exportacines de los bienes producidos por las PYMES (conf. art. 4).

Se entiende que como la adquisición de capital a la incorporación de bienes físicos a la empresa (maquinaria, equipos), los cuales serán aplicados para la producción de bienes y servicios propios de la PYME. En cuanto al capital de trabajo alude al dinero que se utilza en los gastos correntes como ser pago de sueldos, compra de materia pire o mo

La reconversión y aumento de la productividad la cual se vincula con el aumento de la productividad, lo cual puede comprender la actualización tecnológica siendo posible realizarlo a través de créditos amplios que merezcan plazos de amortización y períodos de gracia.

Por su parte la actualización y modernización tecnológica alude a la tecnología empleada por la empresa, a los procedimientos administrativos, a la organización y procedimientos gerenciales y comerciales y contratación de servicios de consultoría.

Revista da Faculdade de Direito da UFRGS, v. 21, Março/2002
Coincidentemente la Ley dispone que se establecerá, a través de los organismos competentes, políticas específicas de apoyo a la internacionalización comercial de las PYMES con particular acento en el proceso de inserción en los mercados de la región (Art. 20).

Se diseñarán y desarrollarán instrumentos que induzcan y faciliten el proceso de especialización de estas empresas a fin de incrementar su competitividad y su acceso a los mercados externos a partir del Mercosur (Art. 21). Asimismo, a través del PEN y del Ministerio de Economía se desarrollará un Programa Nacional de Capacitación de los cuadros empresarios y gerenciales de las PYMES tanto en forma centralizada o descentralizada a través de convenios con Provincias, Municipalidades y Universidades (Art. 22).

Se arbitrarán los medios que promuevan la reconversión de las PYMES en consonancia con la preservación del medio ambiente y los estandares internacionales que rijan en la materia, facultándose a la autoridad de aplicación a fijar políticas tendientes a dictar normas de lealtad comercial y defensa de la competencia a fin de regular las relaciones entre las PyMEs y las grandes empresas.

\section{B - TITULO II}

fondo de riesgo y beneficios, III - De los órganos sociales, IV - De la fusión, escisión y disolución, V - Del contrato, la garantía y la contragarantía, VI - De los efectos del contrato entre la sociedad de garantía recíproca y el acreedor, VII - De los efectos entre la sociedad de garantía recíproca y los socios, VIII - De la extinción del contrato de garantía recírpoca, IX - Beneficios impositivos y Banco Central, X - Autoridad de aplicación, XI - Disposiciones finales.

Como ya lo adelantáramos este título crea un nuevo tipo societario que se agrega a la tipología prevista por la ley 19.550 .

Esta sociedad de garantía recíproca tiene por finalidad facilitar a las PyMEs el acceso al crédito.

Este nuevo tipo societario se regirá por las disposiciones de este título y en forma supletoria por la ley de Sociedades, en particular las normas relativas a la sociedad anónima.

Se trata de un sociedad cuyo objeto queda limitado a lo impuesto por la ley, que conforme el art. 33, será el otorgamiento de garantías a sus socios partícipes mediante la celeración de contratos regulados en la ley.

Asimismo, prevee la posibilidad de brindar asesoramiento técnico, económico y financiero a sus socios en forma directa o a través de terceros contratados a tal fin. Esta enumeración no es taxativa sino que se podrán adoptar otros servicios que sean compatibles con el objetivo y características de la sociedad de garantía recíproca (SGR), siempre y cuando sean a favor exclusivo de sus socios.

Estará constituída por dos tipos de socios. Los socios partícipes ${ }^{15}$ y los socios

${ }^{15}$ Art. 37: (Según ley 25.300): “.. Serán socios partícipes únicamente las pequeñas y medianas empresas, sena éstas personas fisicas o jurídicas, que reúnan las condiciones generales que determine la autoridad de aplicación y suscriban acciones. A los efectos de su constitución toda SGR deberá contar con un mínimo de socios participes que fijará la

Revista da Faculdade de Direito da UFRGS, v. 21, Março/2002 
proctectores $^{16}$.

La SGR no podrá celebrar contratos de garantía con los socios protectores. Y es incompatible la condición de socio protector con la de socio partícipe.

Se estable el límite del monto de las garantías, especificando que la SGR no podrá otorgar a un mismo socio partícipe garantías superiores al 5\% del valor total del fondo del riesgo del a SGR, y tampoco podrá asignar obligaciones con el mismo acreedor más del $25 \%$ del valor total del fondo de riesgo.

A fin de compatibilizar las disposiciones contenidas en la ley 24.467 y sus modificaciones

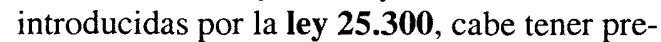
sente también que ésta ley, que tiene por objeto el fortalecimiento competitivo de las micro, pequeñas y medianas empresas (MIPyMEs) que desarrollen actividades productivas en el país, mediante la creación de nuevos instrumentos y la actualización de los vigentes, con la finalidad de alcanzar un desarrollo más integrado, equilibrado, equitativo y eficiente de la estructura productiva, en su art. 2 crea el Fondo Nacional de Desarrollo para la Micro, Pequeña y Mediana Empresa ("fonapyme"), con el objeto de realizar aportes de capital y brindar financiamiento a mediano y largo plazo para inversiones productivas a las empresas y formas asociativas comprendidas en la ley., bajo las modalidades que establezca su reglamentación. Estableciéndose un plazo de extinción de 25 años a contar desde la fecha de su efectiva puesta en funcionamiento, facultándose al PE a extender la vigencia del mismo por períodos adicionales de 25 años.

A tal efecto se establece en el art. 3 que se constituirá un fideicomiso financiero en los términos de la ley 24.441. El Poder Eejecutivo, mediante el Ministerio de Economía, será el

fiduciante, encomendará al Banco de la Nación Argetina, que será el fiduciario, la emisión de certificados de participación en el dominio fiduciario del fonapyme, dominio que estará constituido por las acciones y títulos representativos de las inversiones que realice.

Se designó como fideicomisario al Estado Nacional, por lo tanto será el destinatario final de los fondos integrantes del Fonapyme en caso de su extinción o liquidación, los cuales deberán destinarse a programas de apoyo y desarrollo de las MIPyMEs.

Y en suart. 3 crea el Fondo de Garantía para la Micro, Pequeña y Mediana Empresa (Fogapyme), con el objeto de otorgar garantía en respaldo de las que emitan las sociedades de garantía recíproca y ofrecer garantías directas a las entidades financieras acreedoras de las a las entidades financieras acreedoras de las
MIPyMEs y formas asociativas comprendidas en el art. 1 de la ley, a fin de mejorar las condiciones de acceso al crédito.

Estableciéndose un plazo de extinción de 25 años a contar desde la fecha de su efectiva puesta en funcionamiento, facultándose al PE a extender su vigencia por períodos adicionales de 25 años.

A tal efecto establece en el art. 9 que se constituirá un fideicomiso en los términos de la ley 24.441. El Poder Eejecutivo, a través del Ministerio de Economía, será el fiduciante, dispondrá la transmisión en propiedad fiduciaria de los activos del fogapyme, para respaldar el otorgamiento de las garantías dadas por las SGR.

El Banco de la Nación Argentinas será el fiduciario del fogapyme y deberá prestar todos los servicios de soporte administrativo y de gestión que el comité de administración requiera para el cumplimiento de sus funciones.

${ }^{16}$ Art. 37: (Según ley 25.300) “...Serán socios protectores todas aquellas personas físicas o jurídicas, públicas o privadas nacionales o extranjeras, que realicen aportes al capital y al fondo de riesgo.

Revista da Faculdade de Direito da UFRGS, v. 21, Março/2002
El fideicomisario será el Estado Nacional, que por lo tanto será es destinatario final de los fondos integrantes del Fogapyme en caso de extinción o liqudación, los que deberán destinarse a programas de apoyo al desarrollo de las MIPyMEs.

\section{C - TITULO III}

Este título, se ocupa específicamente de las RELACIONES DE TRABAJO en las pequeñas empresas ${ }^{17}$.

Comprende desde el art. 83 al 106, se encuentra dividido en once secciones. Cuyos acápites son los siguientes: I - Definición de Pequeña Empresa, II - Registro Unico de Personal, III - Modalidades de Contratación. IV - Disponibilidad Colectiva V - Movilidad In- terna, VI - Preaviso, VII - Formación Profesional, VIII - Mantenimiento y Regulación del Empleo, IX - Negociación Colectiva, X - Salud y Seguridad en el Trabajo, XI - Seguimiento y aplicación.

Dado que las pequeñas y medianas empresas proporcionan una buena cantidad de empleo remunerado ${ }^{18}$, fue conveniente que estas tengan una normativa específica en lo que hace a las relaciones laborales y en la aplicación de los programas de fomento del empleo.

\section{I - Definición de pequeña empresa}

El art. 83 de la ley delimita el ámbito de aplicación, estableciendo que: El contrato de trabajo y las relaciones laborales en la pequeña y mediana empresa se regulará por el régimen especial de la presente ley.
17 "Las relaciones laborales que se dan en el ámbito de las pequeñas empresas no pueden prescindir del contexto generl en el cual las normas regulatorias se insertan y en la disciplina que las orienta: el Derecho del Trabajo. El Derecho del Trabajo nació para proteger al trabajador que se desempeña por cuenta y riesgo ajeno. Se lo denominó derecho nuevo por desbordar los moldes clásicos, era un derecho social distinto, ...., que se distinguía del derecho común que supone la igualdad de las partes, porque precisamente parte de la idea de la desigualdad (económica) de ellas. Esta nueva rama del ordenamiento jurídico cuenta con principio y normas jurídicos destinados a regir la conducta humana dentro de un sector determinado de la sociedad, el que se limita al trabajo prestado por trabajadores dependientes, .... La vinculación jurídica de los sujetos de este derecho especial se somete a disposiciones de orden público, por ello la autonomía de la voluntad de las partes se encuentra limitada y restringida por normas inderogables, que impiden, o mejor dicho hasta hoy impedian, la negociación in pejus.." (Paula Costanza Sardegna.- "PyMEs. Relaciones laborales en las pequeñas empresas".- Ed. Universidad Marzo 2001, pág.1/2.-

${ }^{18} \mathrm{Al}$ respecto señala Juan M. Farina.- Raúl Fernandez Campón y Milton A. Rainolter en Régimen de Pequeñas y Medianas Empresas. Ley 24.467. pág. 198 y sig. ".. las pequeñas y medianas empresas dan empleo a gran parte de la población activa. Así por ejemplo, en el sector industrial español, estas empresas dan empleo a las dos terceras partes de la poblacion del sector industrial. La consideracion de otros sectores productivos, para
los que no hay estadisticas fiables, aumentaría considerablemente ese porcentaje en el caso de España (Pérez Simaro, los servicios públicos de empleo,pág. 79).

Un aspecto aún más importante de la contribución de las PyMEs a la oferta de empleos, es el resultado obtenido por los escasos estudios empíricos realizados, según los cuales son las empresas de menor dimensión las que crean mayor número de puestos de trabajo (Pérez Simaro, los servicios públicos de empleo,pág. 83) Birch, en un famoso estudio, "THE JOB GENERATION PROCESS, señala que las empresas con menos de veinte trabajadores crearon el 66\% de los empleos netos de Estados Unidos de Amércia durante el periodo 1969-1976, y que las empresas con menos de cincuenta trabajadores crearon el $77,2 \%$ de los empleos netos, durante el mismo período. Resulta obvio que las empresas que generan empleo son las pequeñas, que son las que gozan de un mayor dinamismo y que, por otro lado, son las que mas recelos levantan a los ojos de las entidades financieras, y a las que más dificil llegan las subvenciones públicas para el fomento del empleo. Todo lo expuesto significa que la pequeña y mediana empresa es la que genera, en su mayor parte, la oferta de empleo. 
Las que deberán reunir dos condiciones.

a. Que el plantel no supere de 40 trabajadores. Que podrá ser modificado por negociación colectiva.

b. Que tengan una facturación anual inferior a la cantidad que para cada actividad o sector fije la Comisión especial de seguimiento del art. $104^{19}$.

Asimismo prevee la posibilidad de que las empresas superen ambos márgnes, siempre y cuando no los dupliquen, en este caso podrán permanecer en el régimen durante el plazo de 3 años, transcurrido este plazo dejarán de permanecer al sistema.

- Mediante la Resolución DGI 4083/95 ${ }^{20}$, se fijaron los montos de facturación para cada sector. (Se deroga la Resolución MTSS Ministerio de Trabajo y Seguridad Social- 1/ $95^{21}$ que fijaba los montos máximos de facturación que se requerían para cada sector, a fin de considerar a la empresa dentro del ámbito de aplicación de la ley)

Esta norma en su art. 1 dispone: "Al solo efecto de lo dispuesto por los artículos 8,9,17 y 18 del decreto 493/95y su modificatorio, se consideran pequeñas empresas tanto a las unipersonales como a las personas de existencia ideal cualquiera sea su tipo legal, que reúnan concomitantemente las siguientes condiciones:

1- Haber contado al 31 de Julio de 1995 con un plantel no superior a cuarenta (40) trabajadores, $y$

2- Haber tenido en el año calendario 1994, un importe de facturación, neto del impuesto al valor agregado, inferior al que para cada sector se fija a continuación:

\section{$a$-Sector rural $\$ 2.500 .000$ \\ $b$ - Sector industrial $\$ 5.000 .000$ \\ $c$-Sector comercial \$3.000.000 \\ $d$-Sector servicios $\$ 4.000 .000$}

Las empresas que hubieren realizado en forma concurrente en el curso del citado año calendario dos o más actividades comprendidas en los distintos sectores económicos, deberán comparar los importes facturados - netos del importe al valor agregado de todas las actividades-con el importe asignado al sector en el cual se obtuvo el mayor monto facturado".

En su art. 3 señala y precisa los cálculos a realizarse para el cómputo del personal, indicando: "A los efectos del cómputo de plantel del personal, las empresas deberán tener en cuenta aquel efectivamente ocupado en el conjunto de las actividades que realicen, tanto si se trata de personal permanente, como si lo fuera de carácter temporario o contratado a través de empresas de servicios eventuales.

En el supuesto que la dotación tuviera variaciones por causa de estacionalidad u ocacionalidad de las tareas, el número de personal resultará del cociente entre el total de horas hombre efectivamente ocupadas y el total de horas hombre proyectadas para el año para un individuo.

${ }^{19}$ En realidad tendría que haber dicho art. 105.

El art. 105 de le ley 24.467.- Crea una comisión especial de seguimiento, dicha comisión es la encargada de determinar el monto de la facturación anual.

${ }^{20}$ Publicada en el Boletín Oficial el 17/11/1995

${ }^{21}$ Publicada en el Boletín Oficial el 30/05/1995.

Revista da Faculdade de Direito da UFRGS, v. 21, Março/2002
Las empresas de servicios eventuales considerarán, a los fines previstos en el punto 1 del art. 1 exclusivamente el personal permanente continuo".

$\mathrm{Y}$ en su art. 4, describe como debe realizarse el cálculo de la facturación, indicando: "En el supuesto de haberse indicado las actividades durante el año calendario 1994, la facturación anual surgirá de proporcionar a ese período el monto efectivamente facturado.

Aquellas empresas que hubiesen iniciado su actividad después del 1 de Enero de 1995, computarán el plantel existente al 26 de Setiembre de 1995. En este supuesto, se analizará la facturación en función del periodo de actividad de la empresa, transcurrido entre la fecha de inicio y el 30 de Setiembre de 1995.

Y mediante el Decreto 146/99, se reglamentó el art. 83, expresamente dispone: " $L a$ negociación colectiva de ámbito superior al de empresa podrá establecer que el plantel de la pequeña empresa, para cada una de las ramas o sectores de la actividad, supere lo cuarenta (40) trabajadores a condición de no exceder, en ningún caso, la cantidad de ochenta (80).

Para el cómputo del plantel sólo se deberá excluir a los pasantes.

La negociación colectiva podrá, cuando las circunstancias especiales de la actividad de que se trate asi lo justifique, ex cluir de ese cómputo a los trabajadores de temporada.

El monto de la facturación será el que surja de la declaración anual del impuesto al valor agregado o balance anual, si la actividad se encontrare exenta, y sólo podrá ser fijado por la Comisión Especial de Seguimiento, no pudiendo delegarse tal facultad al ámbito de la negociación colectiva.
El plazo de tres (3) años fijados en el último párrafo del artículo reglamentado se computará: $a$ - en el referente al número de trabajadores, a partirdel mes siguiente en que se supere el parámetro establecido, $b$ - en cuanto al monto de facturación, a partir del mes siguiente en que se supere el tope establcido.

En aquellos casos en que los convenios colectivos vigentes hubiesen fijado una cantidad superior de trabajadores a la autorizada en el primer párrafo de este artículo, al momento de su renovación, deberán ajustar la misma al tope establecido de ochenta (80) trabajadores".

\section{II - Registro único de personal}

El art. 84 establece la posibilidad de sustituir los libros de registros exigidos por las normas legales y convencionales vigentes por un libro que se denominará "Registro único de personal".

La opción surtirá efectos a partir de la fecha en que el empresario rubique el Registro Unico de Personal. Con anterioridad, deberá llevar la documentación laboral mencionada en lso incs. A a D del art. 86 LCT. El Registro podrá consistir en un libro encuadernado, o bien ser llevado por fichas o planillas resultantes de utilizar sistema de computación o microfilmación (conf. Decreto 737/95).

En dicho libro se asentarán la totalidad de los trabajadores al producirse su ingreso y será rubicado por la autoridad administrativa laboral competente.

En caso de incumplimiento tanto de las obligaciones fijadas por la presente ley como las establecidas por la LCT, tendrá dos tipos de sanciones:

1- La exclusión del régimen de la ley 24.467.

2 - Y además será sancionado conforme las penalidades establecidas en las leyes 18.694 , 23.771 y 24.013 


\section{III - Modalidades de la contratación}

$\mathrm{El}$ art. 89 duró poco tiempo ya que se encuentra deogado por la ley 25.013 Nueva Reforma Laboral.

Este art. otorgaba la posibilidad a las pequeñas y medianas empresas de instrumentar la incorporación de trabajadores a través de los contratos promovidos por la ley Nacional de Empleo (24.013) arts. 43 a 65, marcando ciertas ventajas:

a. no se requerirá la habilitación previa por convenio colectivo de trabajo conforme art. 30 de la ley Nacional de Empleo.

b. No hará falta registrar el contrato conforme art. 18 inc. b y 31 de la ley Nacional de Empleo.

c. No regirá la indemnización prevista por dicha ley.

Mediante el decreto reglamentario 737/ 95 (art. 9) se aprobaron los contratos tipo para las modalidades por tiempo determinado como medida de fomento del empleo, de tiempo determinado por lanzamiento de nueva actividad, de práctica laboral para jóvenes y de trabajoformación aplicables a las pequeñas empresas. Y se facultó al Ministerio de Trabajo y Seguridad Social a efectuar las modificaciones de los modelos aprobados. Obviamente que el decreto también a quedado derogado.

\section{IV - Disponibilidad colectiva y}

\section{V-Movilidad interna} podrá:

Mediante convenios colectivos se

- Modificar las formalidades, aviso requisitos y oportunidad del goce de las vacaciones. Se deja a salvo de que por lo menos uno de cada tres períodos se gocen en época de verano. (art. 90).

- Disponer el fraccionamiento de los períodos de pago del aguinaldo siempre que no exceda de tres períodos en el año.(art. 91).

\footnotetext{
Revista da Faculdade de Direito da UFRGS, v. 21, Março/2002
}

- Modificar el régimen de la extinción del contrato de trabajo. (art. 92)

- Podrán redefinir los puestos de trabajo correspondientes a las categorías determinadas en los convenios colectivos de trabajo de trabajo acoradadas entre el empleador y la representación sindical signataria del convenio. (art. 94).

Cabe tener presente que conforme lo dispone el art. 103, los convenios colectivos, durante el plazo de su vigencia, no podrán ser afectados por convenios de otro ámbito.

\section{VI - Preaviso}

Se computará a partir del día siguiente al de su notificación por escrito, y será de un mes.

\section{VII - Formación profesional}

A través del art. 96 se garantiza a los trabajadores el acceso a los programas de formación profesional que cuentan con el financiamiento estatal.

Se requiere de las empresas que tengan trabajadores que asistan a cursos relacionados con la actividad de la pequeña empresa que prestan servicios, la compatibilización de la jornada laboral de acuerdo a las exigencias del curso de perfeccionamiento que encare su dependiente.

Además este art. impone que los convenios colectivos deberán contener un capítulo especial dedicado a la formación y actualización profesional como deber y derecho del trabajador.

\section{VIII - Mantenimiento y regulación del empleo.}

Conforme el art. 97, cuando las pequeñas empresas decidan reestructurar sus plantas por razones tecnológicas, organizativas o de mercado, podrán proponer a la Asociación sindical signataria del convenio colectivo la modificación del mismo.

Si acordaren tal modificación, la empresa no podrá efectuar despidos durante el tiempo que dure la misma.

El art. 98, apartándose del régimen general, de manera sumamente novedos establece: "Cuando las extinciones de los contratos de trabajo hubieren tenido lugar como consecuencia de un procedimiento preventivo de crisis, el Fondo Nacional de Empleo podrá asumir total o parcialmente las indemnizaciones respectivas, o financiar acciones de capacitación y reconversión para los trabajadores despedidos".

Este tema tiene relación con los fondos de garantías previstos en las normas laborales y de la Seguridad Social.

No obstante, será necesaria su reglamentación para que la transparencia del tema sea pauta rectora.

\section{XI - Negociación Colectiva}

Esta sección que abarca los arts. del 99 al 103 ha sido reglamentado por el Decreto $1555 / 96$.

\section{$X$ - Salud y seguridad en el trabajo}

$\mathrm{El}$ art. 104 prevé que las normas de salud y seguridad en el trabajo "deberán fijar plazos que posibiliten la adaptación gradual de las pequeñas empresas la legislación"

Hasta la fecha nada se ha normado.

\section{XI - Seguimiento y aplicación}

Como ya lo adelantármos elart. 105, crea una Comisión Especial de Seguimiento específicamente la ley establece que deberá realizar.
Su objetivo será verificar la efectiva vigencia de la ley.

\section{V - Conclusion}

A lo largo de éstas páginas hemos efectuado un breve análisis de la ley, manteniendo especial atención en las modificaciones que la misma a sufrido, en el corto plazo que tiene de vida.

Creemos que ha quedado claro que las pequeñas empresas contribuyen en la economía del país, en cuanto son las que crean la mayor cantidad de trabajo asalariado.

$\mathrm{Y}$ esta fue una de las razones que se tuvieron en miras al sancionarse la ley 24.467. Dado que las grandes empresas multinacioneles que dominan los mercados impiden el desarrollo y crecimiento de estas micro y pequeñas empresas, ya que carecen de capacidad económica, financiera y tecnológica a fin de negociar en condiciones de igualdad poder competir y evitar su desplazamiento del mercado tanto internacional como interno.

Así mediante esta ley, aquellas empresas que cumplieran con los requisitos exigidos, podrían amparase en sus beneficios. (tales como facilitar el acceso al crédito bancario, bonificaciones en las tasas de interés).

Creemos que pese a la desaparición de gran cantidad de PyMEs en nuestro país en los últimos años, no debemos quedarnos con los brazos cruzados, sino que hay que seguir luchando para fomentar el crecimiento y la creación de nuevos emprendimientos, por lo que es necesario no solo una adecuación en las condiciones laborales sino también incentivar los créditos bancarios a muy largo plazo e intereses de fomento, desgravaciones, incentivos impositivos. Ya que de su actividad depende gran parte de la economía del país. 